\title{
Crystal Vue Technology in the Study of the Uterine- bladder Interface in a Case of Abnormally Invasive Placenta
}

${ }^{1}$ Gabriella Minneci, ${ }^{2}$ Francesca Foti, ${ }^{3}$ Giuseppe Cali

\begin{abstract}
Crystal Vue is an advanced three-dimensional (3D) volumerendering technology that allows to obtain highly detailed information about internal and external structures of fetus or uterus. The picture of the month shows the employment of such emerging technique in the study of the uterine-bladder interface, clearly pointing out its disruption in a case of abnormally invasive placenta (AIP) with bladder invasion.
\end{abstract}

Keywords: Abnormally invasive placenta, Crystal vue, Uterinebladder interface, Virtual cystoscopy.

How to cite this article: Minneci G, Foti F, Cali G. Crystal Vue Technology in the Study of the Uterine-bladder Interface in a Case of Abnormally Invasive Placenta. Donald School J Ultrasound Obstet Gynecol 2017;11(3):177-178.

Source of support: Nil

Conflict of interest: None

\section{INTRODUCTION}

The AIP is today a rising obstetric pathology, mirroring the increase of cesarean sections in the last decades. In consideration of the epidemiologic emergency and the great maternofetal morbidity and mortality, the prenatal diagnosis of acretism is extremely important.

Two-dimensional ultrasonography is the gold standard in the diagnosis of AIP. Nevertheless, tridimensional ultrasonography and 3D power Doppler allow to acquire multiplanar images on coronal, axial, and sagittal planes and with rotational technique permit to visualize the invasion of parametrium and the hypervascularization of the placenta-bladder interface more accurately. ${ }^{1,2}$ A careful study of the degree of bladder invasion is an information with great impact on the subsequent management. The interruption of the uterine-bladder interface depends on

\footnotetext{
${ }^{1,2}$ Fellow and Resident Trainee, ${ }^{3} \mathrm{Head}$ and Consultant

${ }^{1-3}$ Department of Obstetrics and Gynecology, ARNAS Civico Hospital, Palermo, Italy
}

Corresponding Author: Gabriella Minneci, Fellow and Resident Trainee, Department of Obstetrics and Gynecology, ARNAS Civico Hospital, Palermo, Italy, e-mail: gabriellaminneci@libero.it the hypervascularization of the space between myometrium and bladder. Blood vessels can get in touch with the bladder wall in case of percretism.

Recently, 3D high-definition "sonographic virtual cystoscopy" has been proposed in the diagnostic workup of patients with AIP, in order to analyze the vascular topography of the uterine-bladder interface. ${ }^{3}$

Very clear details of such district can be observed employing a new 3D volume-rendering technology called "Crystal Vue." This is an emerging technique based on image-contrast enhancement that can be used for processing and rendering of acquired 3D volumes.

It is mainly used in skeletal and central nervous system imaging, adding anatomical information thanks to the great contrast enhancing power which conventional 3D does not have. ${ }^{4}$

We report the employment of Crystal Vue in the study of the bladder line hypervascularization, creating a highly detailed virtual cystoscopy. In Figure 1 we present and compare images of normal and abnormal uterine-bladder interface, examined using a Samsung WS80 Elite system (Samsung Medison Co. Ltd., Seoul, South Korea) with Crystal Vue software application.

In both cases, the bladder filling is $300 \mathrm{~mL}$, which we consider optimal for the evaluation of the uterinebladder interface. Using Crystal Vue postprocessing on an acquired 3D volume, the second image clearly shows irregularity and disruption of the normal bladder wall architecture in a case of placenta percreta at 33 weeks of gestation in a patient with two previous cesarean sections. The uterine bulging toward the bladder is evident also.

To document the hypervascularization of the serosabladder interface, it helps to clarify preoperatively the degree of myometrial infiltration and involvement of the bladder wall. This knowledge is important for planning the timing of delivery and the surgical approach and for anticipating potential technical difficulties. With this purpose, Crystal Vue could integrate and confirm the evaluation made by two-dimensional and 3D power Doppler ultrasound, improving prenatal diagnosis of AIP. 


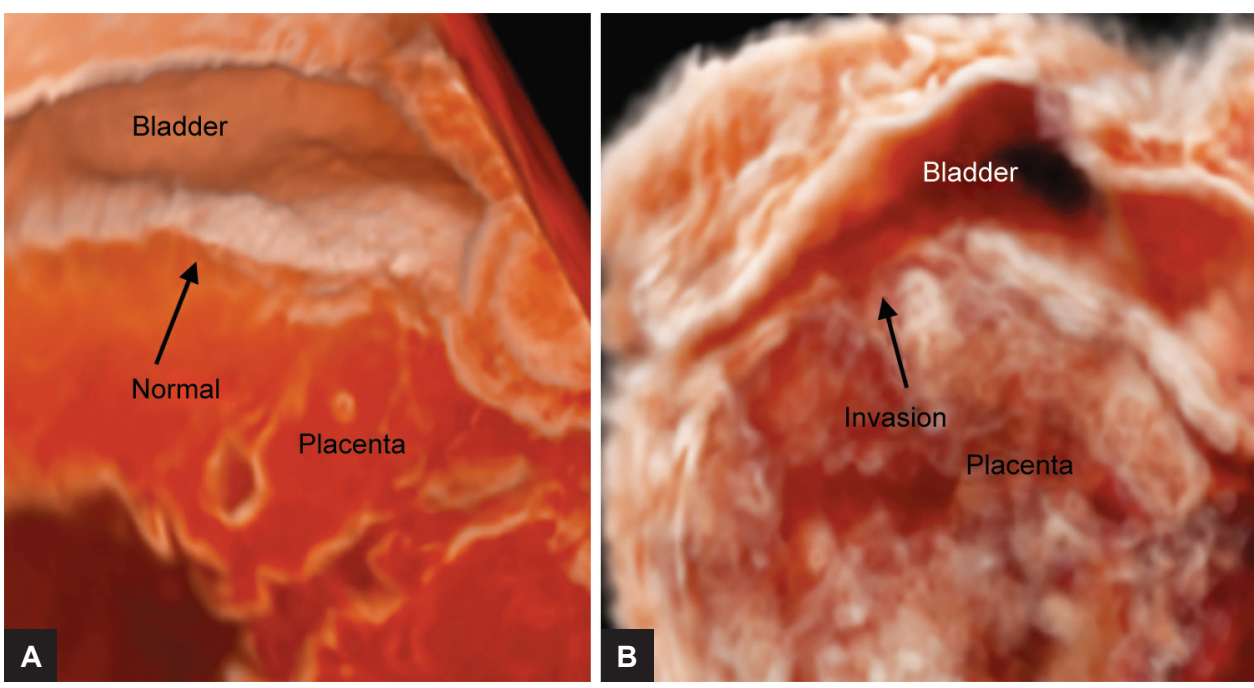

Figs $1 \mathrm{~A}$ and B: Virtual cystoscopy realized with Crystal Vue. Normal (A) and abnormal (B) uterinebladder interface. In picture B, Crystal Vue shows with great detail and efficacy the disruption of the uterine-bladder interface in a case of AIP with bladder invasion

\section{REFERENCES}

1. Calì G, Giambanco L, Puccio G, Forlani F. Morbidly adherent placenta: evaluation of ultrasound diagnostic criteria and differentiation of placenta accreta from percreta. Ultrasound Obstet Gynecol 2013 Apr;41(4):406-412.

2. Calì G, D'Antonio F, Forlani F, Timor-Tritsch IE, PalaciosJaraquemada JM. Ultrasound detection of bladder-uterovaginal anastomoses in morbidly adherent placenta. Fetal Diagn Ther 2016 May;41(3):239-240.

3. Calì G, Forlani F. Picture of the Month. Three-dimensional sonographic virtual cystoscopy in a case of placenta percreta. Ultrasound Obstet Gynecol 2014 Apr;43(4):481-482.

4. Dall'Asta A, Paramasivam G, Lees CC. Picture of the Month. Crystal Vue technique for imaging fetal spine and ribs. Ultrasound Obstet Gynecol 2016 Mar;47(3):383-384. 